\title{
Comparison of sediment transport models on river Omi, South-Western Nigeria
}

\begin{abstract}
Insufficient hydrological record on most Nigerian rivers has discouraged research on sediment transportation study. Hydrometric stations on some major rivers in Nigeria are not functional as expected. Simulation of flow and sediment transport in water bodies can only be achieved by using hydrological records of 15 years at minimum. Fifteen years hydrological records on River Ona were adopted on River Omi due to similar hydrological properties. Hydrological data were measured on the river at seven measuring stations from 2009 - 2015. Existing Sediment transport models were used to simulate total load and a model was also developed based on measured hydrological data. Ackers and White and Shen and Hung method predicted total sediment load of River Omi more than measured values. This may be due to the fact that the variables in the formulae were derived under different conditions from River Omi. Yang and Eugelund and Hansen prediction among the selected methods were relatively close to the measured values. The developed model from measured hydrological data on River Omi water simulate total suspended load than other methods with $70-85 \%$ accuracy.
\end{abstract}

Keywords: sediment transport models, river omi, hydrological record, hydrological, turbidity against gauge
Volume 2 Issue I - 2018S

\author{
Olaniyan OS,Adegbola AA \\ Department of Civil Engineering, Ladoke Akintola University of \\ Technology, Nigeria
}

\begin{abstract}
Correspondence: Olaniyan OS, Department of Civil Engineering, Faculty of Engineering and Technology, Ladoke Akintola University of Technology, Ogbomosho, Oyo State, Nigeria, Email osolaniyan@lautech.edu.ng
\end{abstract}

Received: October 22, 2017 | Published: January 25, 2018

\section{Introduction}

The processes of sediment transport, scour, and deposition in an alluvial channel are extremely complex. Theoretical developments of sediment transport functions for different flow and sediment conditions are based on assumptions of different degrees of complexity. ${ }^{1}$ Some of the simplified assumptions are based on idealized laboratory conditions that may not be true for the much more complicated natural river systems. ${ }^{2,3}$ Ahmed \& Medhaat ${ }^{4}$ and Chang $^{5}$ opined that sediment transport is an important part in the quantitave and qualitative management of river engineering. The rate of sediment transport in water bodies depends on availability of transport materials and transport capability of the water bodies. For a scientific approach to sedimentation, morphology and behaviour of the river must be understood. Morphology (of river) is a field of science which deals with the change of river plan form and cross sections due to sedimentation and erosion. In this field, dynamics of flow and sediment transport are the principal elements. ${ }^{6}$ The morphological studies, therefore, play an important role in planning, designing and maintaining river engineering structures. In recent years, there has been a growing awareness about the need for taking up morphological study of rivers in the country, especially with particular reference to their unique problems. ${ }^{7,8}$

Sediment transport is divided into different categories. The transport modes of particular relevance in morphological modelling are suspended load materials and the bed load. Wash load by definition does not interact with sediment on the river bed. Measurements of sediment transport rate at different locations are useful for calibration of the sediment transport model. ${ }^{9}$ Incidence of flooding has been on the increase in Ibadan, Oyo State Nigeria recently; and this exemplifies the problem operating in most urban centres in Nigeria. Problems associated with high runoff discharge have been a common occurrence in some parts of Nigeria like Ilorin, Ibadan, Lokoja, Delta, Benue and Bayelsa, to mention a few. This extreme hydro-climatic event exemplifies the problem currently operating not only in Nigeria but also in most developing countries of the world. The need for studies relating to river catchment analysis therefore becomes pertinent. ${ }^{10}$ Most rivers in South-Western Nigeria particularly River Omi, River Ogunpa and River Oba are not fully gauged, with the resultant evidence of little or no hydrological record. Hydrometric stations are not adequate and those that are monitored have interrupted hydrological records. Olaniyan ${ }^{9}$ described that there are three sediment transport modes. They are wash load, bed load and suspended load. Wash load are very fine particles which are transported by the water, but these particles do not exist on the bed. Therefore the knowledge of bed material composition does not permit any prediction of wash load transport. ${ }^{11}$ Yang \& Simoes ${ }^{12}$ described bed load as part of the total load which has more or less continuous contact with the bed. Thus the bed load must be determined in relation to the effective shear stress which acts directly on the grain surface. Suspended load are part of the total load which is moving without continuous contact with the bed as the result of the agitation of the fluid turbulence. ${ }^{13}$ The basic idea of splitting the total sediment load into bed-load and suspended load is that, as described above, two different mechanisms are effective during the transport. ${ }^{9,14}$

\section{Brief description of the study area}

This research is designed for River Omi located within Iddo Local Government area of Ibadan. It lies between longitude $3^{\circ} 28^{\prime} 45^{\prime \prime}$ $4^{\circ} 10^{\prime} 14^{\prime \prime}$ East and Latitude $7^{\circ} 01^{\prime} 44^{\prime \prime}-7^{\circ} 45^{\prime} 28^{\prime \prime}$ North of the equator. The river is about $14.5 \mathrm{~km}$ with frequent flooding experience like August, 2011 flooding in Ibadan. The catchment area of the river is $123.53 \mathrm{~km}^{2}$. The river ranges from $(0.50-2.00) \mathrm{m}$ spot height and 19 $\mathrm{km}$ from the source to the study area. ${ }^{15}$ River Omi is an alluvial river with channels and floodplains that are self-formed in unconsolidated or weakly-consolidated sediments (Figure 1).

\section{Scope of research}

This research work considered non-cohesive sediment and utilized effective mean diameter. Sixteen years (16years) river hydraulic 
data from River Ona were adopted on River Omi due to their similar hydrological characteristics. River Omi is a tributary of River Ona both located in Ibadan. Five (5) years of hydraulic data measured on River Omi from June 2010 were used for this study.

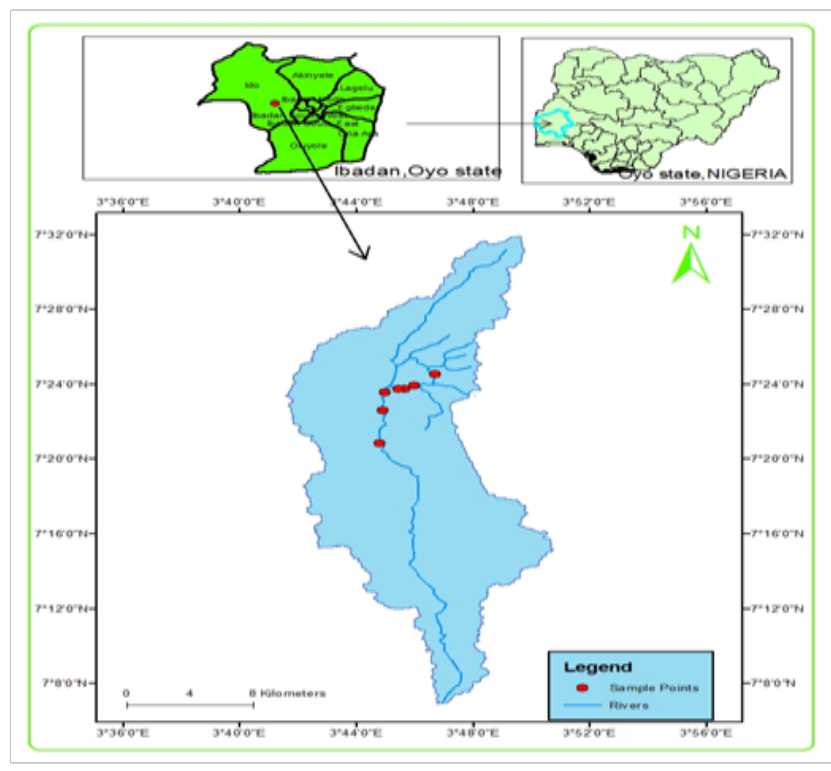

Figure I Hydrological Map of part of Ibadan showing Sampling Stations on River Omi.

\section{Methodology}

Hydraulics and sediment transport data sets including discharge, bed load, suspended load and total load were collected from the measuring locations on the River omi from 2009 to 2014. Gauge and discharge records from 1970-1986 were plotted in Microsoft excel and mathematical equation between the two records was obtained. The equation was analysed using running method according to Subramanya. ${ }^{16}$ It was calibrated and validated using measured hydrological data from 2010-2013 and 2014, respectively. This was in agreement with approach by Subramanya ${ }^{16}$ and Adegbola \& Olaniyan ${ }^{17}$ to deal with hydrological catchments with inadequate data. Flow meter (model 32986) was used to measure the velocity at each cross section. Flow depth was measured using surveying equipment; wetted area and perimeter were also determined.The measuring points on the river are shown in Table 1. Insufficient data is a pertinent problem for hydrologist most especially discharges. Wilson (1990) opined that it is possible to reproduce series of data exhibiting variation as the natural data. Synthetic data in this study were generated using Institute of Hydrology equation was used to predict discharge as shown in equation 1. In this study, the synthesis data was neither use for calibration or validation. The synthesis data only shows the rainfall intensity and catchment properties over the years.

$$
\begin{aligned}
& Q=0.00066 \text { Area }^{0.92} \text { SAAR }^{1.22} \text { SOIL }^{2.0} \\
& S O I L=\frac{0.15 \mathrm{~S}_{1}+0.30 \mathrm{~S}_{2}+0.40 \mathrm{~S}_{3}+0.45 \mathrm{~S}_{4}+0.5 \mathrm{~S}_{5}}{\mathrm{~S}_{1}+\mathrm{S}_{2}+\mathrm{S}_{3}+\mathrm{S}_{4}+\mathrm{S}_{5}}
\end{aligned}
$$

Where:

$\mathrm{S}_{1}-\mathrm{S}_{5}=$ Proportion of catchment covered by each soil class 1-5

$\mathrm{S}_{1}=$ Soil class 1 with highest infiltration capacity

\section{$\mathrm{S}_{5}=$ Soil class 5 with highest infiltration capacity}

$\mathrm{SAAR}=$ Average annual rainfall obtained by taken weight average over the catchment

Table I Location of Sampling Stations on River Omi

\begin{tabular}{llll}
\hline \multicolumn{1}{l}{ Sampling station } & & Longitude & Latitude \\
\hline \multirow{4}{*}{ Upstream } & $\left(\mathrm{Z}_{1}\right)$ & 7.425 & 3.795 \\
& $\left(\mathrm{Z}_{2}\right)$ & 7.425 & 3.78 \\
& $\left(\mathrm{Z}_{3}\right)$ & 7.425 & 3.77 \\
& $\left(\mathrm{Z}_{4}\right)$ & 7.425 & 3.786 \\
Mid-stream & $\left(\mathrm{Z}_{5}\right)$ & 7.425 & 3.778 \\
Down-stream & $\left(\mathrm{Z}_{6}\right)$ & 7.425 & 3.773 \\
\hline
\end{tabular}

\section{Total sediment load measurement}

Suspended load was measured by using standard light weight hand held sediment sampler (US DH-48). Depth integrated sampler was used to collect water sample at $0.1,0.5$ and $1.0 \mathrm{~m}$ depth from water surface. The sampling at each depth were done two times, analysed and averaged for Suspended Sediment Concentration (SSC) computation. Sediment sampling was taken twice in a week and this was increase during high during flood events when turbidity changes more quickly. A relationship between turbidity and suspended sediment concentration were established at each location by sampling a wide range of turbidities and sediment concentrations over a year. 50 $\mathrm{ml}$ of thoroughly mixed water samples from each station was filtered through $0.4 \mu \mathrm{m}$, oven dried and weighed to determine the SSC using equation $3 .{ }^{13}$ Turbid meter (HI 93703) was used to measure turbidity of the water sample and a calibration curve was developed.

$$
\text { SSC }=\frac{\{(\text { weightofmembranefilter }+ \text { dryresidue })-\text { weightofmembranefilter }\}(\mathrm{mg}) \times 1000}{\text { VolumeofFilteredwater }(\mathrm{mL})}
$$

$$
\begin{aligned}
& S S C=m g / l / 1000 / 1000=\text { tonne } L^{-1} \\
& \mathrm{SSC}=\text { Suspended Sediment Concentration }(\mathrm{mg} / \mathrm{l})
\end{aligned}
$$

Bed materials were collected using Van veen grab samplers at upstream, midstream and downstream. The scoop was used to take bed material samples at each gauging site by positioning it at an angle on the stream bed and the wire pulled in order to raise the shutter. The obtained samples from upstream, midstream and downstream were mixed together and part of the mixture was taken to the laboratory for particle size analysis as shown in Table 2 .

The unmeasured sediment loads discharged at the gauging sites on the river was estimated by using Colby approach as described by Otun \& Adeogun. ${ }^{18}$ The bed load component of the unmeasured sediment is accounted for by analyzing the bed materials sampled at the gauging sites. Meyer-Peter and Müller's 1948, Ackers and White's 1973, Engelund and Hansen's 1972 and Yang's 1979 sand and 1984 gravel transport formulas were used in this study for computing sediment transportation.

Engelund and hansen's approach: Engelund and Hansen (1972) used Bagnold's stream power concept and the similarity principle to obtain a sediment transport function as shown: ${ }^{9}$

$$
f^{i} \phi=0.1 \theta^{(5 / 2)}
$$


Where:

$$
\begin{aligned}
& f^{i}=2 g S D / V^{2} \\
& \varnothing=\frac{q_{t}}{\gamma}\left[\frac{\gamma_{s}-\gamma}{\gamma} g d^{3}\right]^{-0.5} \\
& \theta=\frac{\tau}{\left(\gamma_{s}-\gamma\right) d}
\end{aligned}
$$

Where:

$\mathrm{g}=$ Gravitational acceleration $(\mathrm{m} / \mathrm{s})$,

$\mathrm{S}=$ Energy slope,

$\mathrm{V}=$ Average flow velocity $(\mathrm{m} / \mathrm{s})$,

$\mathrm{q}=$ Total sediment discharge by weight per unit width,

$\gamma_{s}$ and $\gamma=$ Specific weights of sediment and water, respectively,

$\mathrm{d}=$ Median particle diameter, and

$\tau=$ Shear stress along the bed

Table 2 Grain size distribution on River Omi Bed Materials

\begin{tabular}{lll}
\hline $\begin{array}{l}\text { Grain size } \\
(\mathbf{m m})\end{array}$ & $\begin{array}{l}\text { Average grain size } \\
(\mathbf{m m})\end{array}$ & Percentage distribution \\
\hline $\mathrm{D}>2.00$ & - & 17.29 \\
$2.00>\mathrm{D}>0.600$ & 0.92 & 32.5 \\
$0.600>\mathrm{D}>0.200$ & 0.36 & 39.3 \\
$0.200>\mathrm{D}$ & - & \\
\hline
\end{tabular}

$\mathrm{D} 50=0.40 \mathrm{~mm}, \mathrm{D} 65=0.90 \mathrm{~mm}, \mathrm{D} 95=1.90 \mathrm{~mm}$

Ackers and white's approach: This approach applied dimensional analysis to express mobility and sediment transport rate in terms of some dimensionless parameters Yang. ${ }^{19}$ The mobility number for sediment transport is given as:

$$
F_{g r}=U_{0}^{n}\left[g d\left(\frac{\gamma_{s}}{\gamma}-1\right)\right]^{-1 / 2}\left[\frac{V}{\sqrt{32} \log \log (\alpha D / d)}\right]^{1-n}
$$

Where:

$\mathrm{U}_{0}=$ Shear velocity

$\mathrm{n}=$ Transition exponent, depending on sediment size

$\mathrm{a}=$ Coefficient in rough turbulent equation $(=10)$,

$\mathrm{d}=$ Sediment particle size, and

$\mathrm{D}=$ Water depth

The dimensionless grain diameter which expresses grain size is given as:

$$
d_{g r}=d\left[\frac{g\left(\gamma_{s} / \gamma-1\right)}{v^{2}}\right]^{1 / 3}
$$

Where

$\mathrm{v}=$ Kinematic viscosity

The generalized dimensionless sediment transport function can be simply expressed as:

$$
G_{g r}=C\left(\frac{F_{g r}}{A}-1\right)^{m}
$$

Ackers and White (1973) used laboratory data to determine the values of $\mathrm{A}, \mathrm{C}, \mathrm{m}$, and $\mathrm{n}$ with sediment size greater than $0.04 \mathrm{~mm}$ and Froude number less than 0.8 . For the transition zone with $1<\mathrm{d}_{\mathrm{gr}} \leq 60$,

$$
\begin{aligned}
& \mathrm{n}=1.00-0.56 \log d_{\mathrm{gr}} \\
& A=0.23 d_{g} r^{(-1 / 2)}+0.143
\end{aligned}
$$

For coarse sediment, $\mathrm{d}_{\mathrm{gr}}>60$

$\mathrm{n}=0, \mathrm{~A}=0.17, \mathrm{~m}=1.5$ and $\mathrm{C}=0.025$

For the transition zone:

$$
m=\frac{9.66}{d_{g r}}+1.34
$$

$\log \log C=2.86 \log \log d_{g r}-\left(\log \log d_{g r}\right)^{2}-3.53$

Yang approach: Yang ${ }^{20,21}$ extended his dimensionless unit stream power equation for sand transport to gravel transport. The gravel and sand equations thus obtained is:

$\log \log C_{t g}=6.681-0.633 \log \log \frac{\omega d}{v}-4.816 \log \log \frac{U_{*}}{\omega}+\left(2.784-0.305 \log \log \frac{\omega d}{v}-0.282 \log \log \frac{U_{*}}{\omega}\right) \log \log \left(\frac{V S}{\omega}-\frac{V_{c r} S}{\omega}\right)$

$\log \log C_{t s}=5.435-0.286 \log \log \frac{\omega d}{v}-0.457 \log \log \frac{U_{*}}{\omega}+\left(1.799-0.409 \log \log \frac{\omega d}{v}-0.314 \log \log \frac{U_{*}}{\omega}\right) \log \log \left(\frac{V S}{\omega}-\frac{V_{c r} S}{\omega}\right)$ is:

Yang (1996) extended his dimensionless unit stream power equation for sand transport to gravel transport. The gravel equation thus obtained

$\log \log C_{t}=5.165-0.153 \log \log \frac{\omega d}{v}-0.297 \log \log \frac{U_{*}}{\omega}+\left(1.780-0.36 \log \log \frac{\omega d}{v}-0.48 \log \log \frac{U_{*}}{\omega}\right) \log \log \left(\frac{V S}{\omega}-\frac{\gamma}{\gamma_{S}-\gamma}\right)$ 
Where:

$\mathrm{C}_{\mathrm{t}}=$ Total sediment concentration, with wash load excluded (in ppm by weight)

$\mathrm{VS}=$ Unit stream power,

$\mathrm{U}^{*}=$ Shear velocity,

$\mathrm{v}=$ Kinematic viscosity,

$\omega=$ Fall velocity of sediment, and

$\mathrm{d}=$ Median particle diameter $(\mathrm{m})$.

Meyer-peter and miiller formula: Meyer-Peter and Miiller (1948) formulated an empirical formula for the bed load discharge in natural streams. ${ }^{9}$ Their formula for a rectangular channel is given as:

$\gamma \frac{Q_{s}}{Q}\left(\frac{K_{s}}{K_{r}}\right)^{3 / 2} d S=0.047 \gamma_{s}^{i} D_{m}+0.25\left(\frac{\gamma}{g}\right)^{1 / 3} g_{s}^{2 / 3}$

But $D_{m}=\sum_{i=1}^{n} D_{s i} i_{b}$

Where

$\gamma=$ The specific weight of water $\left(\mathrm{t} / \mathrm{m}^{3}\right)$

$\mathrm{Q}_{\mathrm{s}}=$ That part of the water discharge apportioned to the bed $(1 / \mathrm{s})$,

$\mathrm{Q}=$ The total water discharge $(1 / \mathrm{s})$,

$\mathrm{K}_{\mathrm{s}}=$ Strickler's coefficient of bed roughness, equal to 1 divided by Manning's roughness coefficient $\mathrm{n}$,

$\mathrm{K}_{\mathrm{r}}=$ The coefficient of particle roughness, equal to $\left(26 / \mathrm{D}_{90}\right)^{1 / 6}$,

$\mathrm{D}_{90}=$ Particle size, in $\mathrm{m}$, for which $90 \%$ of the bed mixture is finer,

$\mathrm{d}=$ The mean depth $(\mathrm{m})$

$\mathrm{S}=$ Energy gradient in $\mathrm{m}$ per $\mathrm{m}$

$g_{s}=\left[0.368 \frac{Q_{s}}{Q}\left(\frac{D_{90}^{1 / 6}}{n_{s}}\right)^{3 / 2} d S-0.0698 D_{m}\right]^{3 / 2}$

Where:

$\mathrm{g}_{\mathrm{s}}=$ The bed load discharge for dry weight, in $\mathrm{m} / \mathrm{s}$ per $\mathrm{m}$ of width,

$\mathrm{Q}, \mathrm{Q}_{\mathrm{s}}=$ Sediment and water discharges, respectively, in $1 / \mathrm{s}$,

$\mathrm{D}_{90}, \mathrm{D}_{\mathrm{m}}=$ Sediment particle diameter at which $90 \%$ of the material, by weight, is finer and

mean particle diameter, respectively,

$\mathrm{d}=$ Water depth and

$\mathrm{n}_{\mathrm{s}}=$ Manning's roughness value for the bed of the stream

$C_{s}=\frac{8 L a \sqrt{g}}{\left(\rho_{s}-\rho\right) \sqrt{\rho}}\left(\rho J R-0.047 D_{50}\left(\rho_{S}-\rho\right)\right)^{3 / 2}$

Where:

$\mathrm{C}_{\mathrm{s}}=$ Sediment transport capacity $\left(\mathrm{m}^{3} / \mathrm{s}\right)$

$\mathrm{D}_{50}=$ Median diameter of sediment $(\mathrm{m})$
$\mathrm{J}=$ Friction slope

$\mathrm{La}=$ Active width $(\mathrm{m})$

$\rho_{\mathrm{s}}=$ Density of sediment $\left(\mathrm{kg} / \mathrm{m}^{3}\right)$

$\rho=$ Density of water $\left(\mathrm{kg} / \mathrm{m}^{3}\right)$

This equation is better simplified as:

$C_{s}=\left[\sqrt{(s-1)} g d^{3}\right] 8\left(\tau^{*}-\tau_{\text {critical }}^{*}\right)^{3 / 2}$

Where

$\tau^{*}=\frac{R_{h} S}{(s-1) d}, \tau_{\text {critical }}^{*}=0.047$

$\mathrm{q}_{\mathrm{b}}=$ Bed flux (volume rate of transport per unit length of surface)

$\mathrm{d}=$ Particle diameter $(\mathrm{m})$

$\rho_{\mathrm{s}}=$ Sediment density $\mathrm{kg} / \mathrm{m}^{3}$

$\mathrm{s}=(\rho \mathrm{s} / \rho)=$ relative density

$\mathrm{S}=$ Channel slope

The total carrying capacity or sediment concentration for a particular river section, $\mathrm{C}_{\mathrm{t}}$, is computed by using the formula:

$C_{t}=\sum_{i=1}^{N} P_{i} C_{i}$

Where:

$\mathrm{p}_{\mathrm{i}}=$ Percentage of material of size fraction I available in the bed;

$\mathrm{C}_{\mathrm{i}}=$ Sediment concentration or carrying capacity for each size fraction; and

$\mathrm{N}=$ Number of size fractions

Shen and hung equation: Shen and Hung regression analysis developed the empirical equation 16 to compute the total sediment load as shown in equation 16 (Olaniyan, 2014):

$\log \mathrm{C}_{\mathrm{t}}=-107,404.45938164+324,214.74734085 \mathrm{Y}$ $-326,309.58908739 \mathrm{Y}^{2}+109,503.87232539 \mathrm{Y}^{3}$

Where :

$\mathrm{Y}=\left(\mathrm{VS}^{0.57} / \omega^{0.32}\right)^{0.00750189}$

$\mathrm{C}_{\mathrm{t}}=$ Total sediment concentration in ppm by weight, and

$\omega=$ Average fall velocity of sediment particle

Regression analysis: Sediment transport function developed from regression analysis on River Omi based on measured hydrological data from 2009 - 2014 was also used in the model. The equation was developed using regression analysis. Turbidity records were plotted against velocity and gauging depth respectively as shown in Figure 2. Equations 17(a) and b were obtained from regression analysis of measured hydrological data as shown in Figure 2.

$$
\begin{aligned}
& y_{1}=8.386 \ln x_{1}+29.84 \\
& y_{2}=14.57 \ln x_{2}+62.23
\end{aligned}
$$

Where:

$\mathrm{y}_{1}$ and $\mathrm{y}_{2}=$ turbidity (FTU) 
$\mathrm{x}_{1}=$ gauge depth $(\mathrm{m}), \mathrm{x}_{2}=$ velocity $(\mathrm{m} / \mathrm{s})$

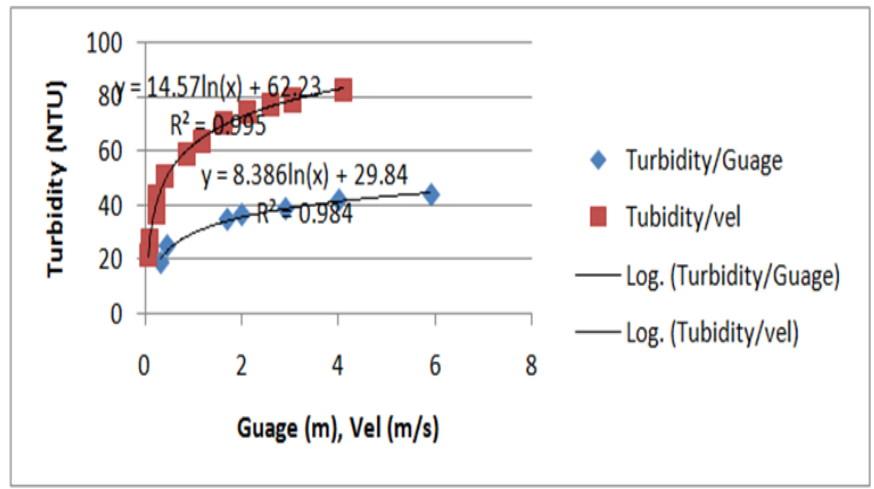

Figure 2 Turbidity against Gauge and Velocity.

It was equally realized from literature the velocity-depth ratio affects sediment transport in a river. This ratio was considered in the development of the model. A strong relationship exists between turbidity and velocity with a $71 \%$ coefficient of regression. The model was calibrated by minimizing the residual between the measured and simulated values. The equation developed from measured stage, discharge and suspended sediment concentration after calibration was:

$y\left(\frac{m g}{l}\right)=\frac{0.8659 \ln \ln (h)+2.866}{(v / h)^{n}}$

$\mathrm{h}=$ Depth of water $(\mathrm{m})$

$\mathrm{v}=$ Average velocity $(\mathrm{m} / \mathrm{s})$

$\mathrm{n}=$ Exponent

$n=0.5$, if $v / h \leq 0.4$

$n=-3.375$, if $0.4<v / h \geq 1.9$

$n=-0.9$, if $v / h>1.9$

The statistical package employed in this study to analyse results obtained from sediment transport function is t-test and Analysis of Variance (ANOVA). The alpha value $(\alpha)$ used for the analysis for each sediment functions was 0.05 .

\section{Results and discussion}

The Total Sediment Load comprises of suspended load and bed load. The average monthly suspended sediment concentration across the river is shown in Figure 3. The upstream suspended sediment value ranges from $(1.1-8.1) \mathrm{mg} / \mathrm{l}$. The $\mathrm{SSC}$ value at the midstream is the lowest across the river section with the value ranges from $(0.3-$ $3.5) \mathrm{mg} / \mathrm{l}$. At the downstream, the suspended sediment concentration varies from $(0.3-6.1) \mathrm{mg} / \mathrm{l}$. The spatial variation of suspended sediment concentration across River Omi can be explained by the Land Use map of the catchment areas shown in Figure 4. The midstream and downstream of River Omi were dominated by vegetal cover which is a potential source of wash load.

The calibration curve was obtained by plotting series of Suspended
Sediment Concentration (SSC) against Turbidity over a period of time. The measured turbidity and Suspended Sediment Concentration (SSC) during flooding are outliers and are not considered in the generation of calibration curve. This curve was used to convert Turbidity (NTU) to Suspended Sediment Concentration (SSC) $\mathrm{mg} / \mathrm{l}$ when the hand held US DH- 48 sediment sampler is not available. Turbidity measured on River Omi ranges from $(0.2$ - 94) NTU and the Suspended Sediment Concentration (SSC) varies from $(0.05-8.2) \mathrm{mg} / 1$.

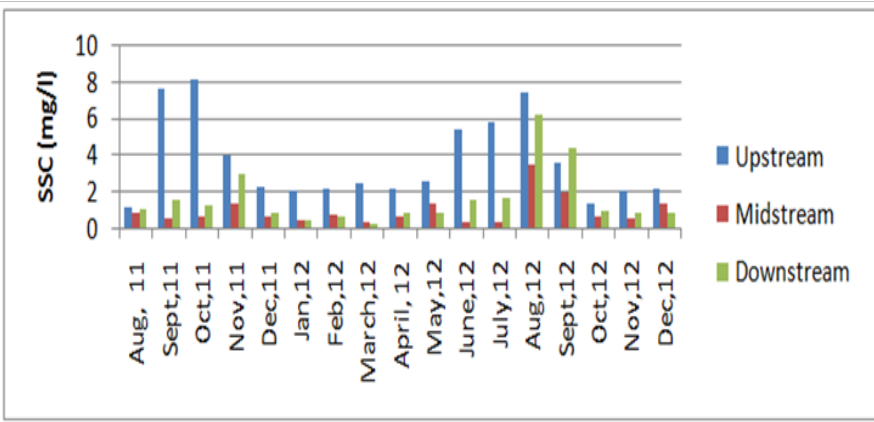

Figure 3 Monthly Suspended Sediment Load across River Omi.

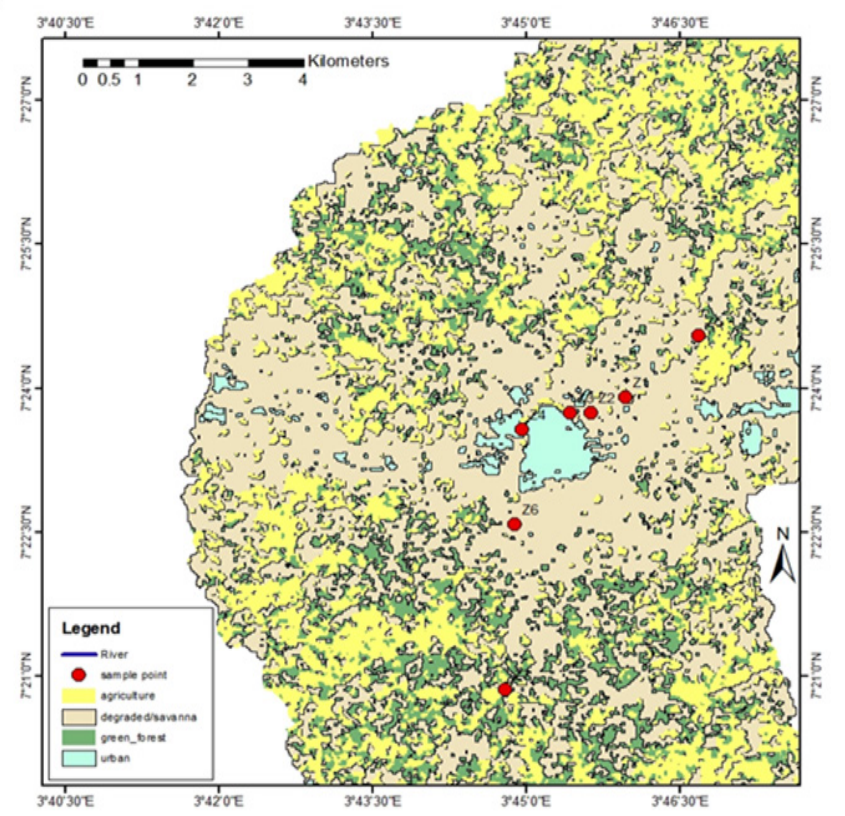

Figure 4 Land-Use Map of River Omi Catchment Area.

The Suspended Sediment Concentration (SSC) at the upstream is higher than the midstream and downstream. The upstream suspended sediment value ranges from $(1.1-8.1) \mathrm{mg} / \mathrm{l}$. The SSC value at the midstream is the lowest across the river section with the value ranges from $(0.3-3.5) \mathrm{mg} / \mathrm{l}$. At the downstream, the suspended sediment concentration varies from $(0.3-6.1) \mathrm{mg} / \mathrm{l}$. The spatial variation of suspended sediment concentration across River Omi can be explained by the Land Use map of the catchment area (Figure 4). The sampling points are located within built up and vegetal area. The midstream and downstream are located within vegetal area and were affected by wash load due to soil erosion. The upstream sampling points are located within built up environment and are affected by anthropogenic activities such as improper waste disposal which block their channel.

\section{Comparison of sediment transport function}

The bed load coefficient of River Omi watershed was estimated 
from Meyer peters and Millers equation. The estimated bed flux on River Omi was $9 \%$ of the total load. Similar study by Otun \& Adeogun ${ }^{18}$ on Kubani River estimated the bed load flux as $7 \%$ of the total load. The total sediment concentration in this study was calculated by the selected formulas (Engelund and Hassen, Ackers and White, Yang, Shen-Hung equation and Regression analysis). The estimated total load by these four methods along was compared with measured values on field. However, Ackers and White and Shen and Hung method predicted total sediment load of River Omi more than measured values. This may be due to the fact that the variables in the formulae were derived under different conditions from River Omi. The prediction process of sediment load by Ackers and White is unclear and imprecise. Acker and White formula was determined under a laboratory condition. The coefficient in the formula is not applicable in River Omi with open channel flow. Shen and Hung equation over predicted the total sediment load which confirms that it was developed under different site condition compare to River Omi. Yang and Eugelund and Hansen prediction among the selected methods were relatively close to the measured values (Figure 3). Yang equation on the other hand gave erroneous result at lower velocity when the ratio

$$
\begin{aligned}
& V S / \omega<2.05 S . \\
& \text { Where: } \\
& \mathrm{V}=\text { Velocity }(\mathrm{m} / \mathrm{s}), \mathrm{S}=\text { slope, and } \omega=\text { settling velocity }
\end{aligned}
$$

Yang equation of 1973 is characterized with incipient motion criteria and is more accurate when the sediment concentration is less than $100 \mathrm{ppm}$. The dimensionally non homogeneous parameters used and the lack of ability to reflect the effect of depth change limit the application of Shen and Hung equation to laboratory flumes and small rivers with particles in the sand size range. The developed regression analysis from measured stage-discharge values (equation 18) on River Omi water shed gave closest value to the measured total suspended load. The regression equation considered velocity-gauge ratio to simulate suspended sediment transport.

Sediment discharge in natural river is hinged on gradation and shape factor of sediment, percentage of bed surface covered by coarse materials, existence of wash load, availability of bed materials, temperature, and hydrologic cycle. There is much uncertainty to estimation of sediment discharge at different flow, hydrological and climatic constraint. Figure 5 shows comparisons of sediment transport functions used in this study. The obtained value from Shen and Hung are too large as compared to others, which explain the reason for semi-logarithmic plot of Figure 5. Acker and White together with Eugelund and Hansen formula under estimate the total suspended load across River Omi. The best result was obtained from the developed regression analysis on the measured parameters on River Omi. Yang and Eugelund and Hansen formula over estimate at lower Suspended Sediment Concentration.

Table 3 shows the statistical analysis of result from different sediment transport function used. The $\mathrm{P}$ value of the sediment function developed from regression analysis was greater than $\alpha$ value. This implies that the sediment function developed from regression analysis gave a closer result as compared to the measured value. Yang approaches together with Eugelund and Hansen prediction were relatively closer to the measured value in that order. Other sediment transport function as Shen and Hung approach and Acker and White approach prediction are far from the reality on River Omi watershed.
The obtained $\mathrm{P}$ value was very low for Acker and White, Shen and Hung, Eugelund and Hansen formula. This is because Acker and White method was developed based on laboratory experiment which is different from the field situation on River Omi. The Shen and Hung regression analysis equation was developed on a small river which has a different hydrological condition from the present study.

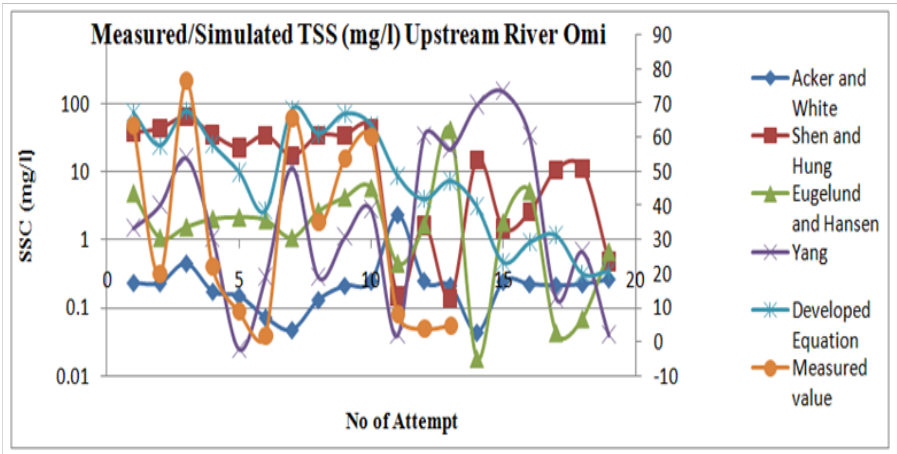

Figure 5 Comparison of Results from Used Model.

Table 3 Statistical Analysis of Sediment Transport Function

\begin{tabular}{llllll}
\hline & A and W & S and H & E and H & Yang & $\begin{array}{l}\text { Regrs. } \\
\text { Analysis }\end{array}$ \\
\hline Pooled Var. & 381.7 & 559.43 & 438.7 & 437.6 & 88.31 \\
t-stat & 4.201 & 0.506 & 3.31 & 3.097 & -0.254 \\
PT $<=t)$ & 0.0003 & 0.0006 & 0.0029 & 0.0049 & 0.801 \\
t (crit.) & 2.063 & 2.063 & 20.63 & 2.063 & 2.063 \\
\hline A and W,Acker and White; $S$ and H, Shen and Hung; E and H, Eugelund and
\end{tabular}

Hansen; Regrs. Analysis, Regression Analysis

\section{Conclusion and recommendations}

Shen and Hung and Ackers and White sediment transport functions overestimated the total sediment load while Eugelund and Hassen and Yang approach underestimated the total sediment load. Shen and Hung regression analysis equation could not predict the total sediment load on River Omi because it was developed under different site condition. The developed regression analysis equation gave a good agreement between measured and simulated values with (3-11)\% variation. Development of sediment regression model using stage-discharge records of a river yielded accurate result. ${ }^{22-25}$

\section{Acknowledgements}

The authors acknowledge our project students and technical staff from Civil Engineering Department of LAUTECH for field study operations.

\section{Conflict of interest}

This research work didn't have conflict of interest of any form.

\section{References}

1. Darus A. Conservation and Restoration of Urban Rivers: Case Study of Raia River and Pari River. Universiti Sains Malaysia, Penang, Malaysia; 2002.

2. Van Rijn LC. Principles of Sediment and Erosion. Engineering in Rivers, Estuaries, Seas and Ocean. Aqua Publications, Loose leaf Edition, Netherland; 2005. 
3. Yazdandoost F. Numerical Simulation of Sediment Transport in Dynamic Flow Conditions. International Journal of Sediment Research. 2005;20(4):358-365.

4. Ahmed-Mustapha AM, Medhat SA. Nile River Sediment Transport Simulation (Case Study of Damietta Branch). Eleven International water Technology Conference. IWTC 2007 Sham El-Sheikh, Egypt; 2007.

5. Chang HH. Case study of Fluvial Modeling of River Responses to Dam Removal. Journal of Hydraulic Engineering. 2008;134(3):295-302.

6. Bahadori F, Ardeshir A, Taheshmasi A. Prediction of Alluvial River Bed variation by SDAR Model. Journal of Hydraulics Research. 2006;44(5):614-623.

7. Adegbola AA, Olaniyan OS. Temporal Variation of Sediment Transport in River Omi, South-Western Nigeria. International Journal of Applied Engineering Research. 2012;7(4):421-431.

8. Van Rijn LC. Principles of Sediment Transport in Rivers, Estuaries and Coastal Seas. Aqua Publications, Amsterdam, Netherlands; 1993.

9. Olaniyan OS. Hydrological Analysis of Sediment Transport in a Turbulent Flow. Master's thesis, Vrije Universiteit Brussels, Belgium; 2009. p. 97.

10. Adeodokun OA, Olanike KA, Adeleye EA, et al. Seasonal Limnologica Variation and Nutrient Load on the River System in Ibadan, Metropolis Nigeria. European Journal of Scientific Research. 2008;4(3):98-108.

11. Yang CT, Simoes FJM. Simulation and prediction of river morphologic changes using GSTARS 2.0. In: Proceedings third international conference on hydro-science and engineering, Cottbus/Berlin, Germany; 1998. p. 1-8.

12. Yang CT, Simoes FJM. Wash Load and Bed-Material Load Transport in the Yellow River. Journal of Hydraulic Engineering. 1998;131(5):413-418.

13. Rahaman Zullyadini A, Ismail Wan Ruslan. Variation of suspended sediment Transport in the Timah Tasoh Reservoir catchment, Perlis, Malaysia: Human impacts and the role of tropical storms. Proceedings of the International Association of Hydrological Sciences. 2006;371-379.
14. Olaniyan OS, Adegbola AA. River Geometry Computation on River Omi South-Western Nigeria. LAP Publisher, Germany; 2012

15. Kumolu O. Simulation of Flow on River Omi. Bachelor of Technology Thesis, Department of Civil Engineering, Ladoke Akintola University of Technology, Ogbomoso, Nigeria; 2008.

16. Subramanya K. Engineering Hydrology. 2nd Ed. Tata McGraw-Hill Publishing Company Limited, New Delhi, India; 2007.

17. Adegbola AA, Olaniyan OS. Computation of River Discharge from For mulated Rating Equation in Hydrological Catchments with Inadequate Data: River Omi, South Western Nigeria, as Case Study. Civil and Environmental Research. 2013;3(7):58-63.

18. Otun JA, Adeogun BK. Analysis of Fluvial Sediment Discharge into Kubani Reservoir. Nigeria Journal of Technology. 2010;29(2):64-75.

19. Yang CT. Sediment Transport and Stream Power. International Journal of Sediment Research. 2002;17:31-38.

20. Yang CT. Incipient Motion and Sediment Transport. Journal of the Hydraulic Division. 1973;10(99):1679-1704.

21. Yang CT. Unit Stream Power Equation for Gravel. Journal of Hydraulic Engineering. 1984;1(10):1783-1797.

22. Dong YH, Lu JY, Fan BL, et al. Research on Variations of Typical Lower Jingjang River Reach after Three Gorges Project Operation. Journal of Yangtze River Scientific Research Institute. 2005;22 (2):9-12.

23. Yang CT. Potential Energy and River Morphology. Water Resources Research. 1971;7(2):311-322.

24. Yang CT. The Movement of Sediment in Rivers. Geophysical Survey. 1979;3(1):39-68.

25. Yang CT. Mechanics of Suspended Sediment Transport. In: Bechteler W, editor. Proceedings of Eurom.ech 192: Transport of Suspended Solids in Open Channels. Munich/Nuremberg, Germany; 1985. p. 87-91. 